\title{
Use of remote sensing and geographical information system (GIS) for salinity assessment of Vaal-Harts irrigation scheme, South Africa
}

\author{
George M Ochieng ${ }^{1}$, Olumuyiwa I Ojo ${ }^{1 *}$, Fredrick AO Otieno ${ }^{2}$ and Beason Mwaka ${ }^{3}$
}

\begin{abstract}
Background: Soil salinity is a critical environmental problem in many countries around the world especially the arid and semi-arid countries like South Africa. The problem has great impact on soil fertility which in turns has a great effect on soil productivity. This paper addresses the use of remote sensing and GIS in the assessment of salinity using Landsat enhanced thematic mapper plus (ETM+) data of the Vaal-Harts irrigation scheme acquired with other field data sets and a topographical map to show the spectral classes and salt-affected areas for the years under assessment (1991 to 2005).

Results: The results of the study indicated that salinity problem exists and may get worse. The supervised classification maps show that most of the salinity problems are located along the entire scheme. The Normalized Difference Vegetation Index (NDVI) tends to be higher along the irrigation canals. A plot of NDVI values and temperature trend give a correlation of $67 \%$ this is an indication that temperature is a major factor in the build up of salinity in the study area. The low salinity class increased by $4,8618 \mathrm{~km}^{2}$, while medium and high salinity classes decreased by $4,296.4 \mathrm{~km}^{2}$ and $485.4 \mathrm{~km}^{2}$, showing an increase in the salinity trend over the years.

Conclusions: Considering the trend of salinity development in VHS, there is an urgent need for management program to be established in order to control the spread of the menace and therefore reclaim the damaged land in order to make the scheme more viable.
\end{abstract}

Keywords: Remote sensing, GIS, Salinity, Vaal Harts, NDVI

\section{Background}

The problem of salinity has great impact on soil fertility which in turns has a great effect on soil productivity. According to a survey by the Department of Agriculture in 1990 , it was discovered that out of 128,000 ha of cultivated land, 54, 000 ha is seriously alkaline, waterlogged and moderately saline ( $\mathrm{Du}$ 1991). An estimated $18 \%$ of the area under regular irrigation appears to be affected by water logging and salinization in the Vaal Harts irrigation scheme. In the 1960s, a number of soil profiles from all over the Scheme, contained more salts in the subsurface than measured during the initial soil survey, indicating a disturbing tendency, although not alarming at that stage. Within 35 years of the scheme's existence, the fine sandy

\footnotetext{
* Correspondence: olumuyiwaojo@gmail.com

${ }^{1}$ Dept. of Civil Engineering, Tshwane University of Technology, Pretoria, South Africa

Full list of author information is available at the end of the article
}

soils of this scheme were severely salinised. Reclamation of some 30000 ha saline or saline-sodic soils (depth $0.3 \mathrm{~m}$ ) was reported at VHS. Salt-affected soils at VHS resulted in 1.4 - 2.1 million South African Rand gross income loss for the irrigation scheme farmers in 1975 ( $\mathrm{Du}$ 1991). The installation of 218 drainage systems totaling $500 \mathrm{~km}$ of subsurface lateral drains at a cost of 2 million Rand were undertaken between 1975 and 1977. In the 1980s, a further 2 million Rand was invested to install sub-surface drains on farms and to link these drains to the partially developed system of open storm water drains, in an attempt to lower the water table and to leach salts. Since 2009, the service of a consultant was engaged to assess the scheme at an additional cost of about 5 million Rand (Ojo et al. 2009, 2011). Salinity problems are often measured by means of soil surveys, questionnaires and laboratory analyses. These traditional data collection methods analyses are neither enough for the assessment of this important environmental 


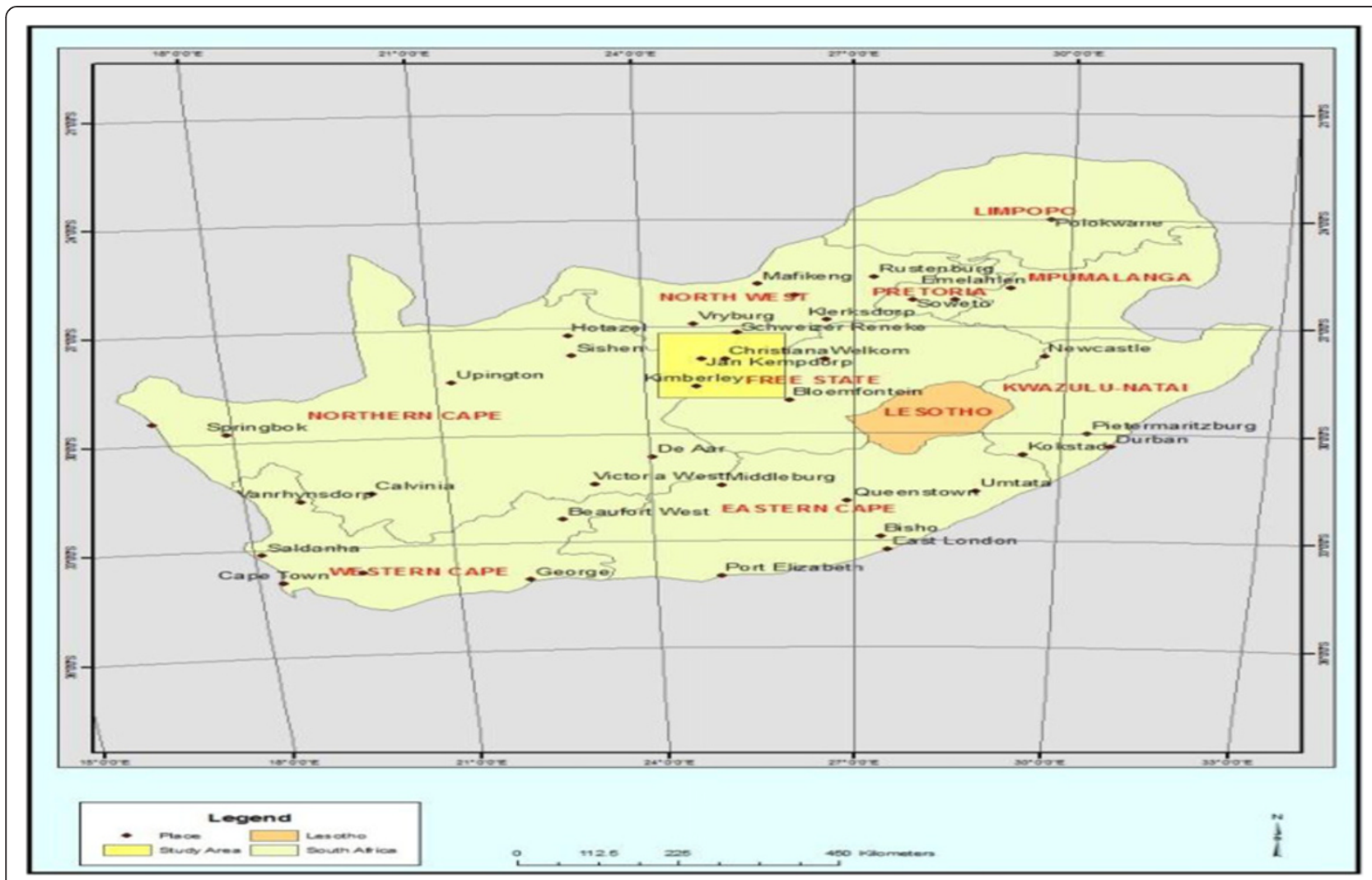

Figure 1 Location of the study area (VHS) in relation to South Africa. Source: adopted from van Vuuren, et al (2004).

issue. Satellite image data are used to overcome most of these limitations with a need to better find the calibration between the data and real field situations. The spread of modeling techniques using distributed parameters has largely encouraged the use of input data from remote sensing with the support of GIS for manipulating large data sets. In the interim report submitted to the Institute for Applied Systems analysis, Brogaard and Prieler (1998) described how Landsat MSS can be used for the identification of broad land cover changes of the Western part of Horqin steppe, Inner Mongolia Autonomous Region. Van Trinh et al. (2004) used Landsat images for studying land use dynamics and soil degradation in the Tamduong district of Vietnam. Eranani and Gabriels (2006) used Landsat data from 1976 to 2002 to detect changes in land cover in the Yazd-Ardakan basin, Iran. Latifovic et al (2005) analysed the land cover change of the Oil Sands Mining Development in Athabasca, Canada using information extraction

Table 1 Landsat time-series used in the study

\begin{tabular}{lllll}
\hline Year & Sensor & Path & Row & Date \\
\hline 1991 & Landsat TM & 172 & 079 & $\mathbf{1 9 9 1 / 0 3 / 0 4}$ \\
2001 & Landsat ETM+ & 172 & 079 & $\mathbf{2 0 0 1 / 0 5 / 2 6}$ \\
2005 & Landsat ETM+ & 172 & 079 & $\mathbf{2 0 0 5 / 0 3 / 0 2}$ \\
\hline
\end{tabular}

method applied to two Landsat scenes. The objective of this study was to assess the salinity problem in Vaal Harts irrigation scheme using multi-temporal satellite data.

\section{Methods}

\section{Study area}

The study area is the Vaal harts irrigation scheme (VHIS). It is in the east of Fhaap Plateau on the Northern Cape and North West province border in South Africa. VHIS covers about 36950 hectare irrigated lands. VHIS is located in a summer rainfall area. This area battles with low, seasonal and irregular rainfall. The average rainfall is $442 \mathrm{~mm}$ per year (Jager, 1994). The average precipitation in the summer months, October to February differs between 9.1 and $9.6 \mathrm{~mm} /$ day while in July precipitation is only $3.6 \mathrm{~mm} /$ day. The VHIS main canal, northern canal and western canal are being used to convey water to the scheme for the use of farmers. The scheme has about 680 farmers with water being abstracted from the Vaal River at the Vaal Harts weir about $8 \mathrm{~km}$ upstream of Warrenton. The capacity of the canals in Vaal Harts is $4 \mathrm{~mm}$ /day. The water quota for the North and West canal is $9140 \mathrm{~m}^{3}$ per ha/annum. The total water use charge is 8.77 cents per cubic meter of water which consists of a charge of 8.24 cents for irrigation water use, a catchment management charge of 0.5 cents per cubic meter and a water 


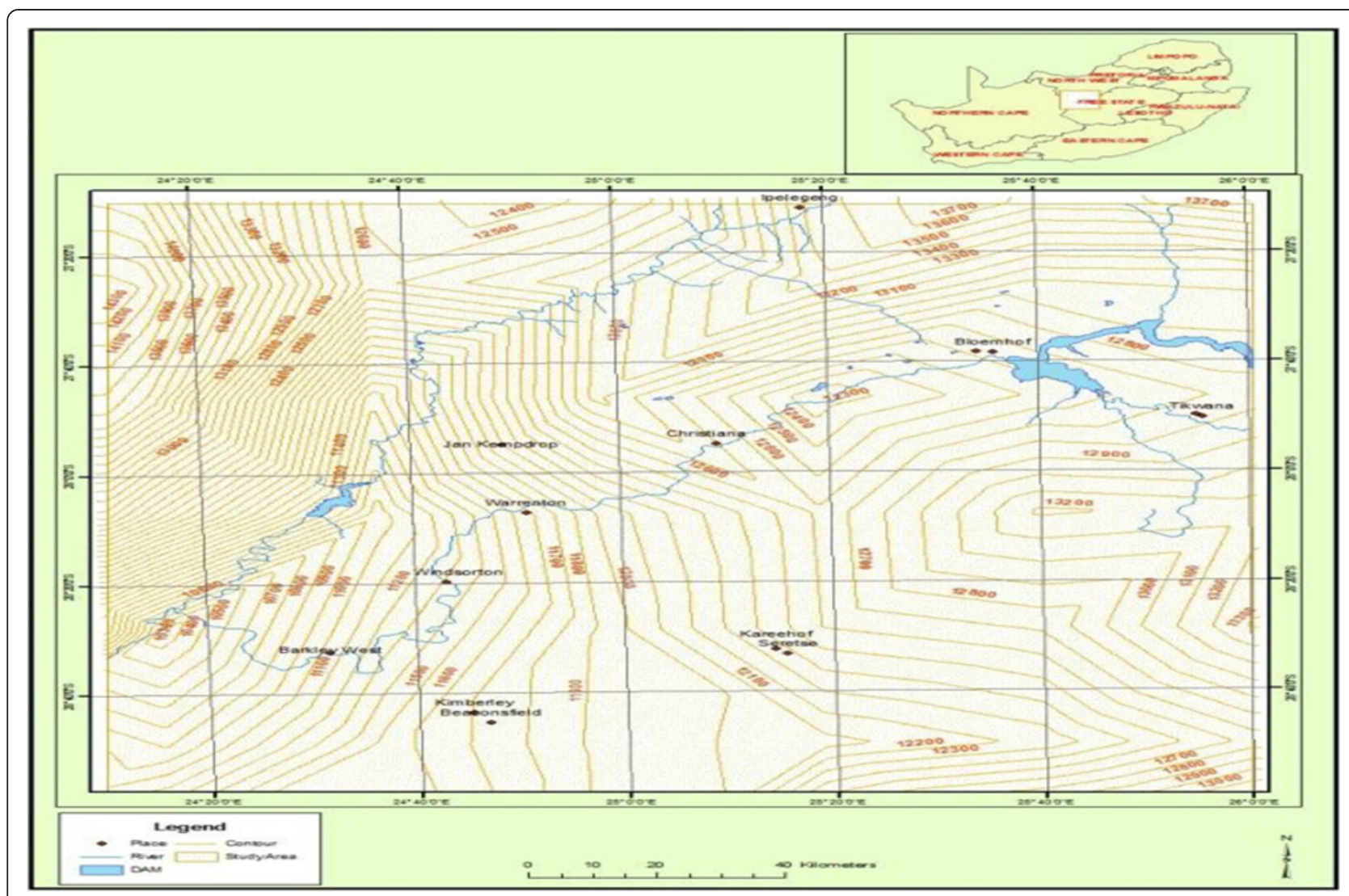

Figure 2 Topographical map of the study area.

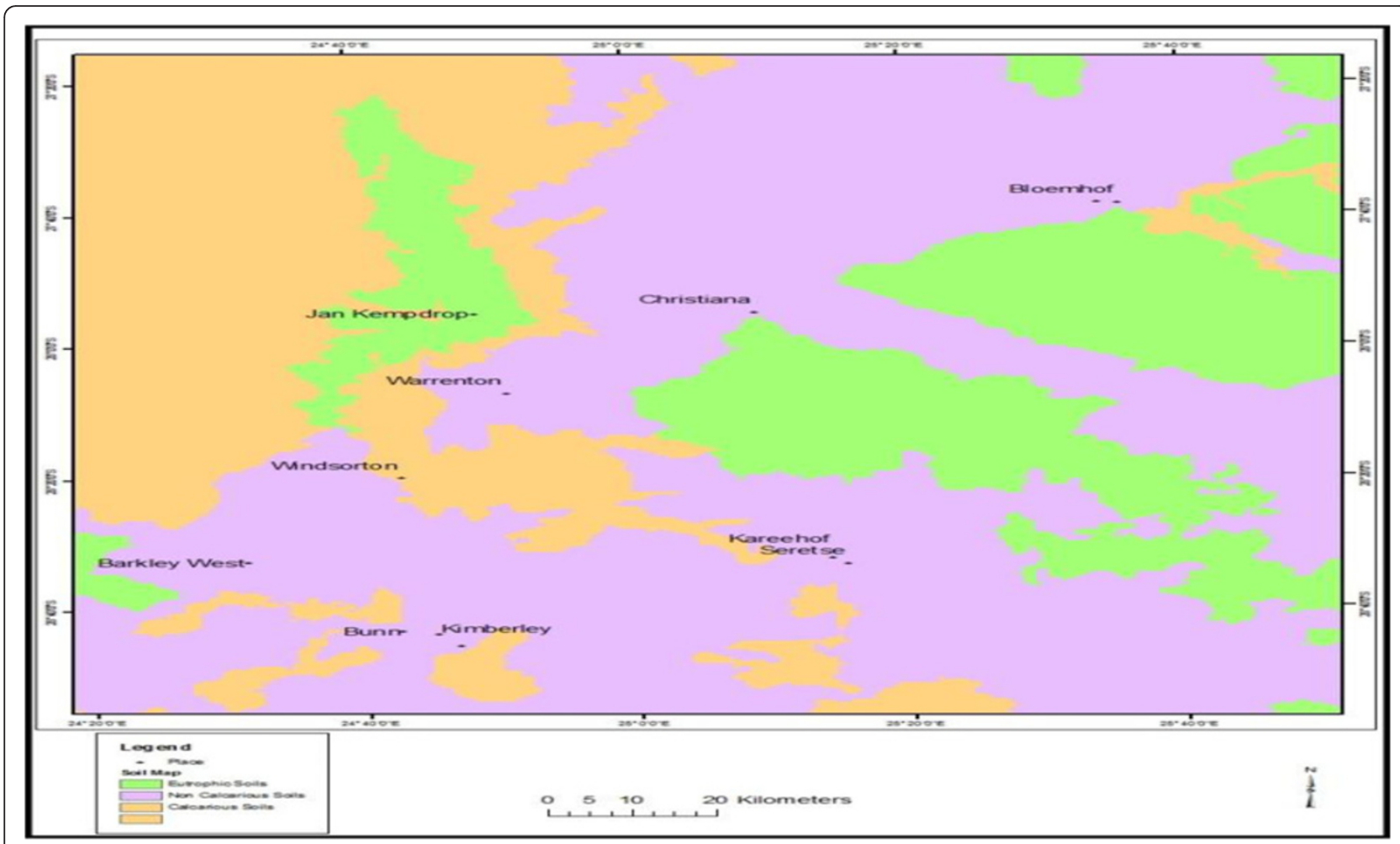

Figure 3 Soil map developed. Source: Dept. Of Agriculture and GIS analysis. 


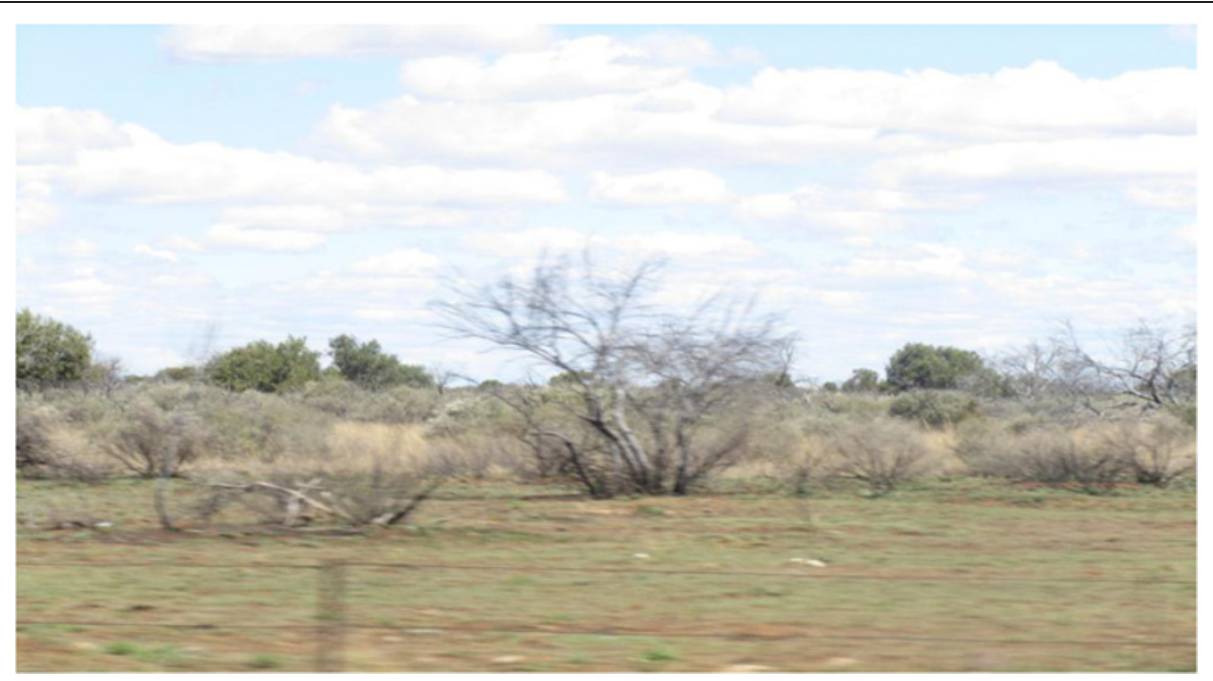

Figure 4 Salinity in VHS. Source: Field survey on: 25 September, 2011.

research charge of 0.03 cents per cubic meter of water. The common crops grown in the area are wheat/barley, maize, groundnuts, cotton and other permanent crops like Lucerne, Pecan nuts, grapes, olives and some other fruits (Grove, 2006). Figure 1 shows the map of study area within South Africa.

\section{Data collection, processing and analysis}

For the study, Landsat (TM and ETM+) images data of VHS with Latitude E $24.7178^{\circ}-272612^{\circ} \mathrm{S}$ and Longtitude S 25. $2765^{\circ}-28.0180^{\circ} \mathrm{E}$ (path 172 , row 079 ) acquired for

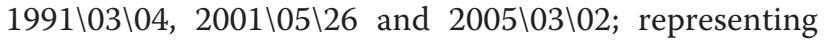
15 years (details of Landsat time-series data used in the study are as shown in Table 1). The data were obtained from the Global Land Cover Facility (GLCF) an Earth Science Data Interface hosted by the University of Maryland, USA and was used to consider variation in salinity as well as in vegetation cover. Some discrepancies of mismatch were found when overlaid on the Geo-referenced image. Topographic maps (as in Figure 2) of Vaal Harts (VHS) with a scale of 1:150,000 was obtained from the Department of Water Affairs and were used to correct the layers. Other information about the scheme water quality, soil types (as shown in Figure 3) \& quality, agricultural practices, crop yield, the scheme facilities and other necessary ground truth data of VHS were obtained through baseline survey and structured questionnaires administered among the farmers and were subsequently used

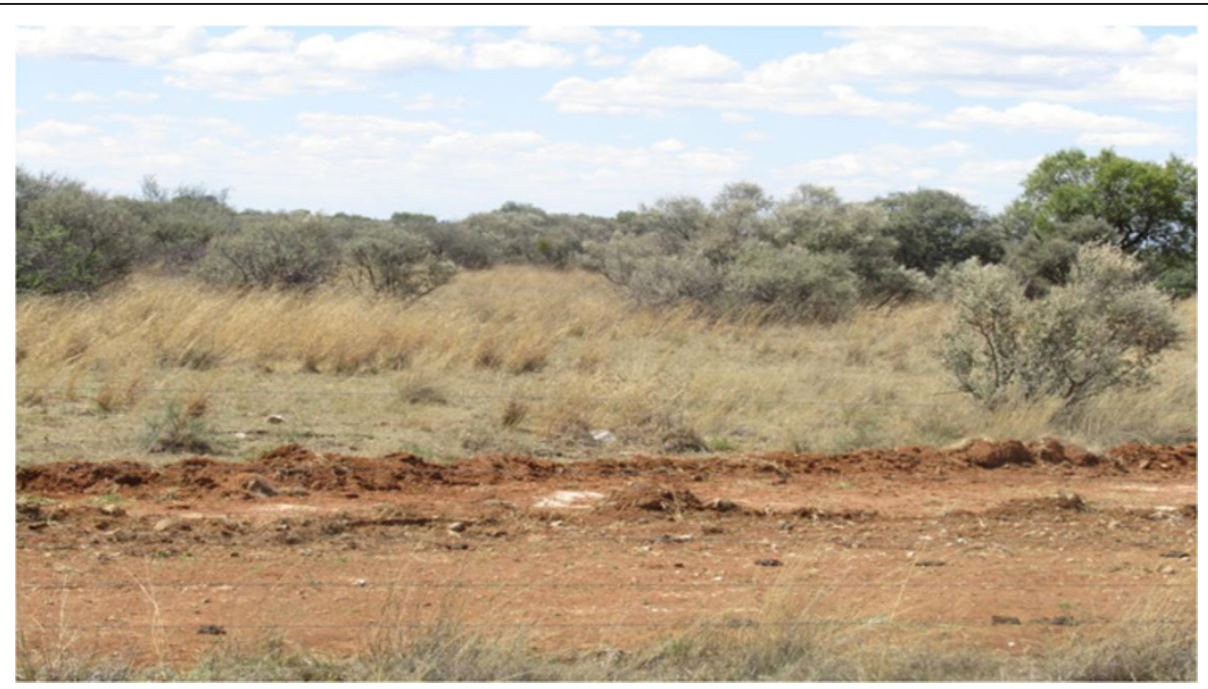

Figure 5 Salinity in VHS. Source: Field survey on: 25 September, 2011. 


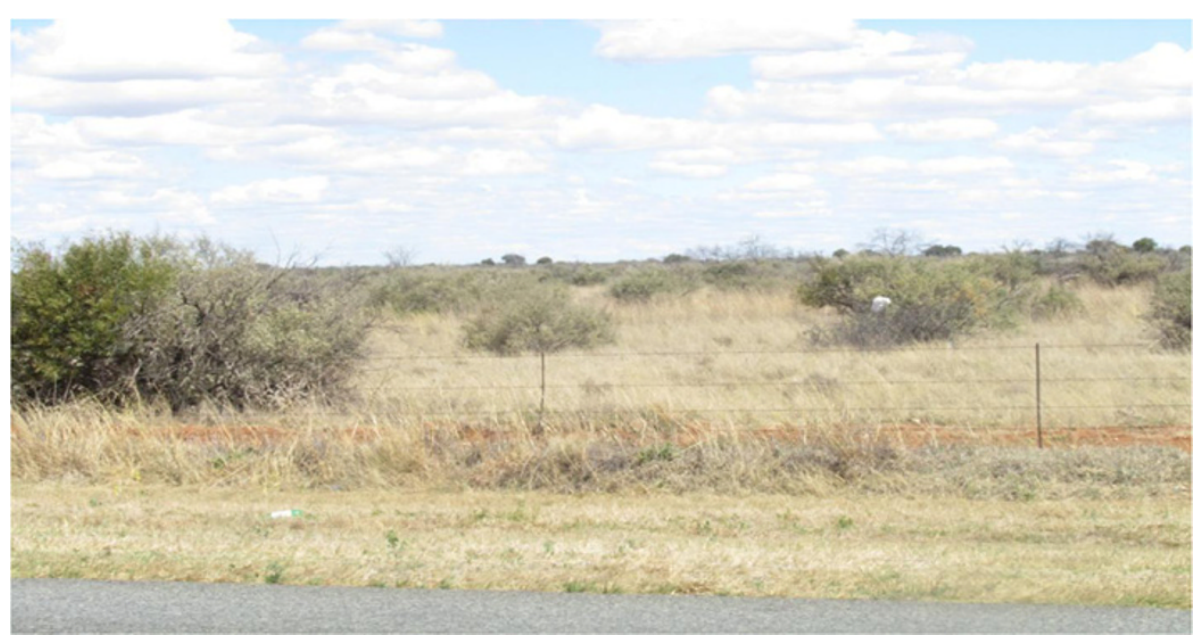

Figure 6 Salinity in VHS. Source: Field survey on: 25 September, 2011

in the remaining part of the study. Soil Map and soil data were obtained from the Agricultural Research Council (ARC) and temperature data from South Africa Weather Service. Figures 4, 5, 6, and 7 give scenes of the current salinity problem in VHS as of September, 2011 during the field survey.

Contrast, brightness enhancements and true colour composite of the images were performed on the images using band 3, 4 and 5 for each scene. Mosaicing of the composite images was done in Erdas Imagine software to achieve a whole image (of four scenes) of the study area as shown in Figure 8. The image was clipped in ArcGIS software to extract the study area from the mosaic image as shown in Figure 9. It was ensured that co-registration of the images were within 0.5 pixels and $30 \mathrm{~m}$ resolution and root mean square errors (RMSE) of all the images were less than 0.5 pixels. The following indices; Salinity Index (SI), Normalised Salinity Differential Index (NSDI) and Normalised Differential Vegetative Index (NDVI) proposed by Tripathi et al. (1997), were applied to give better results in the re-classification of saltaffected lands. SI is the ratio of red band to near infrared (NIR) band while NSDI is the ratio of the difference in the red band to NIR divided by the summation of the two. This concept emerged from the Red Edge concept for vegetation vigour mapping. In red edge concept, the spectral reflectance of NIR is radioed with red band, which gives very high values for vegetation than other features on

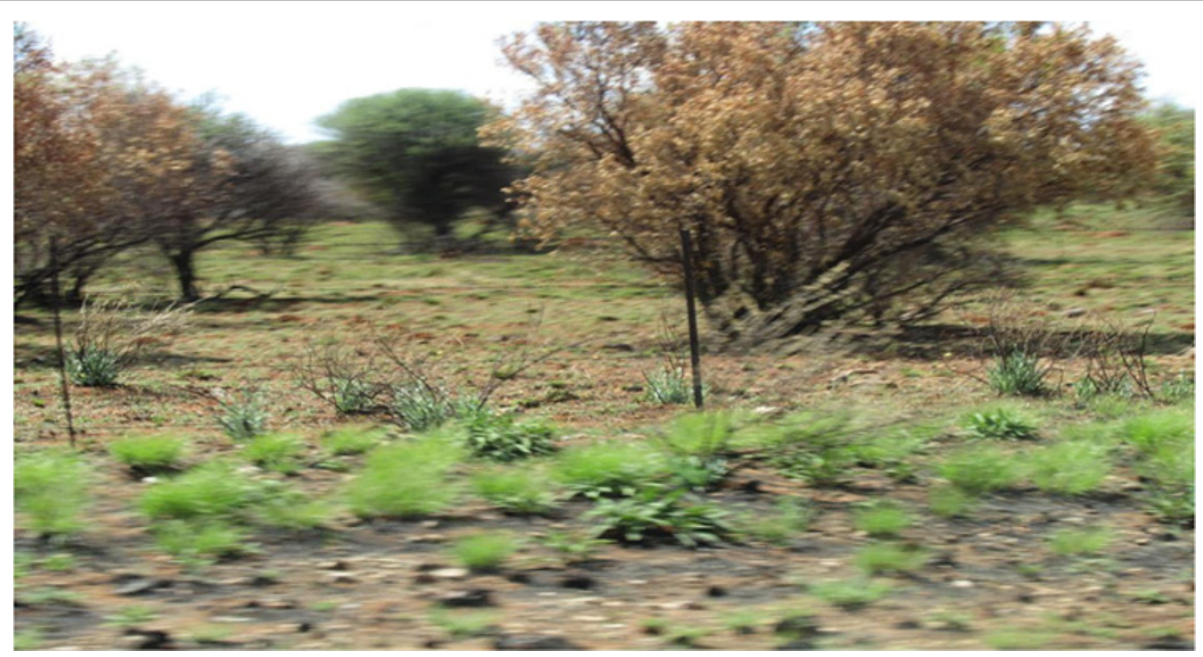

Figure 7 Salinity in VHS. Source: Field survey on: 25 September, 2011. 

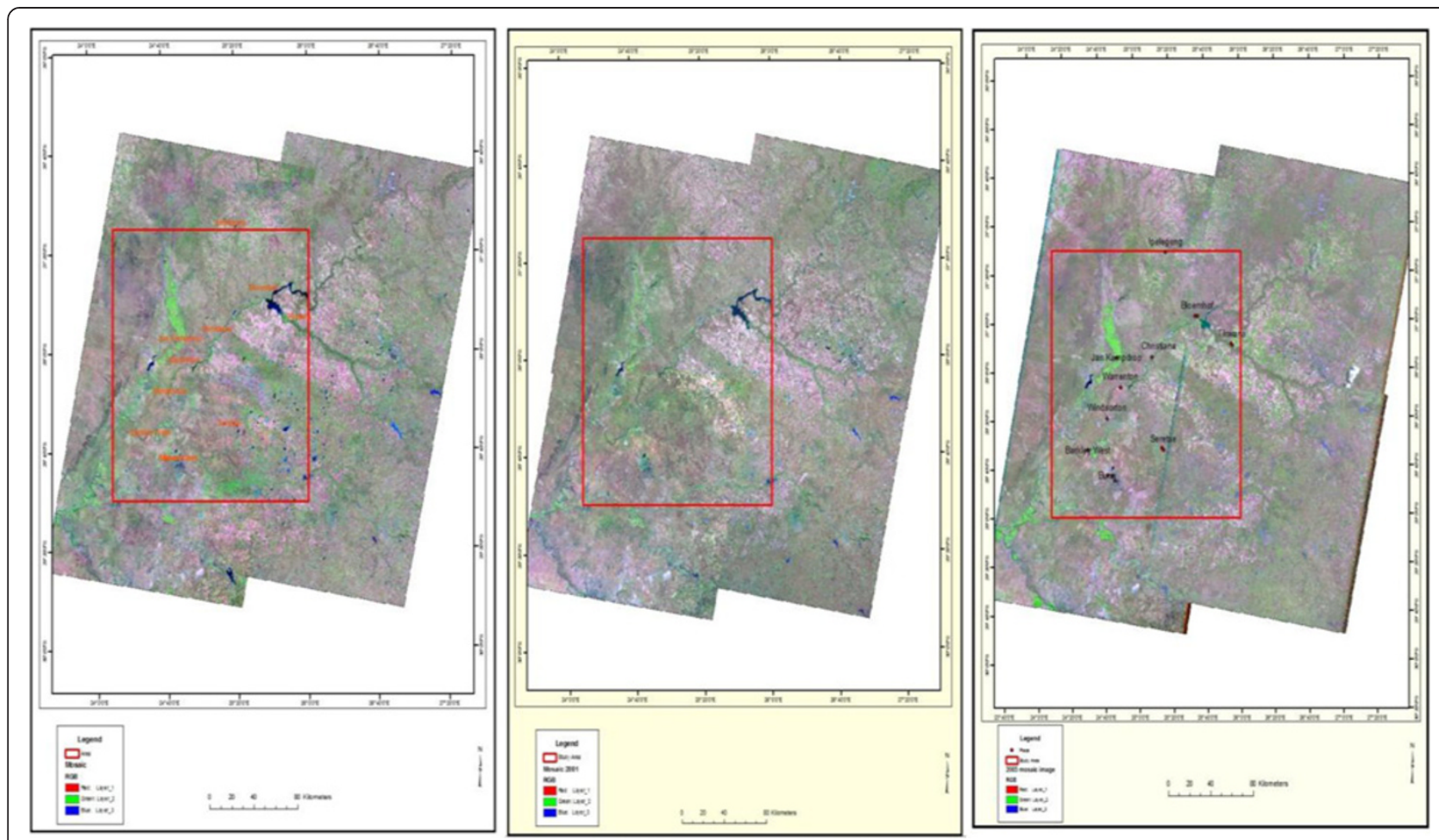

Figure 8 Mosaic images of 1991, 2001 and 2005. Source: GIS analysis.
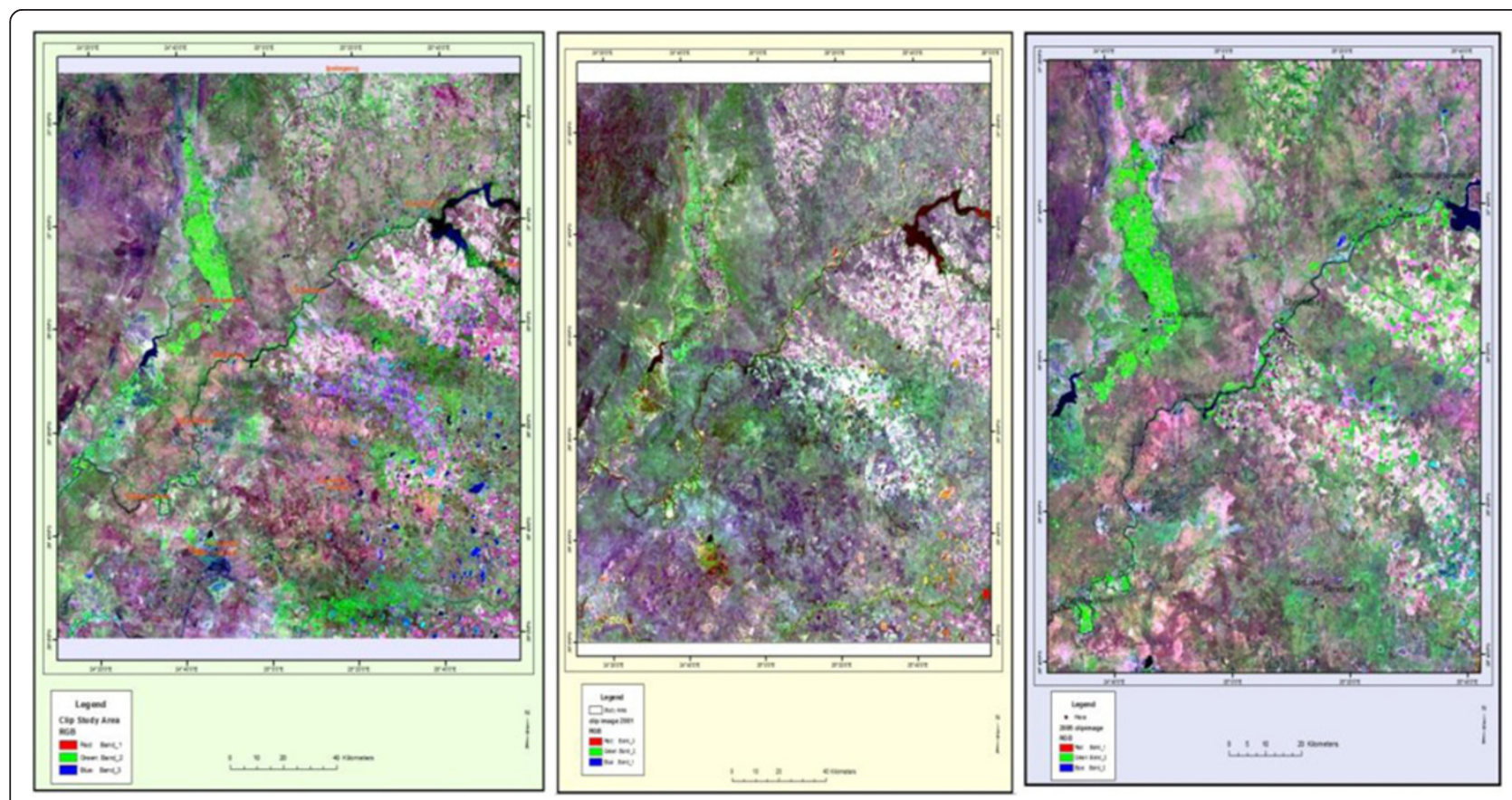

Figure 9 Clipped images of 1991, 2001 and 2005 respectively. Source: GIS analysis. 


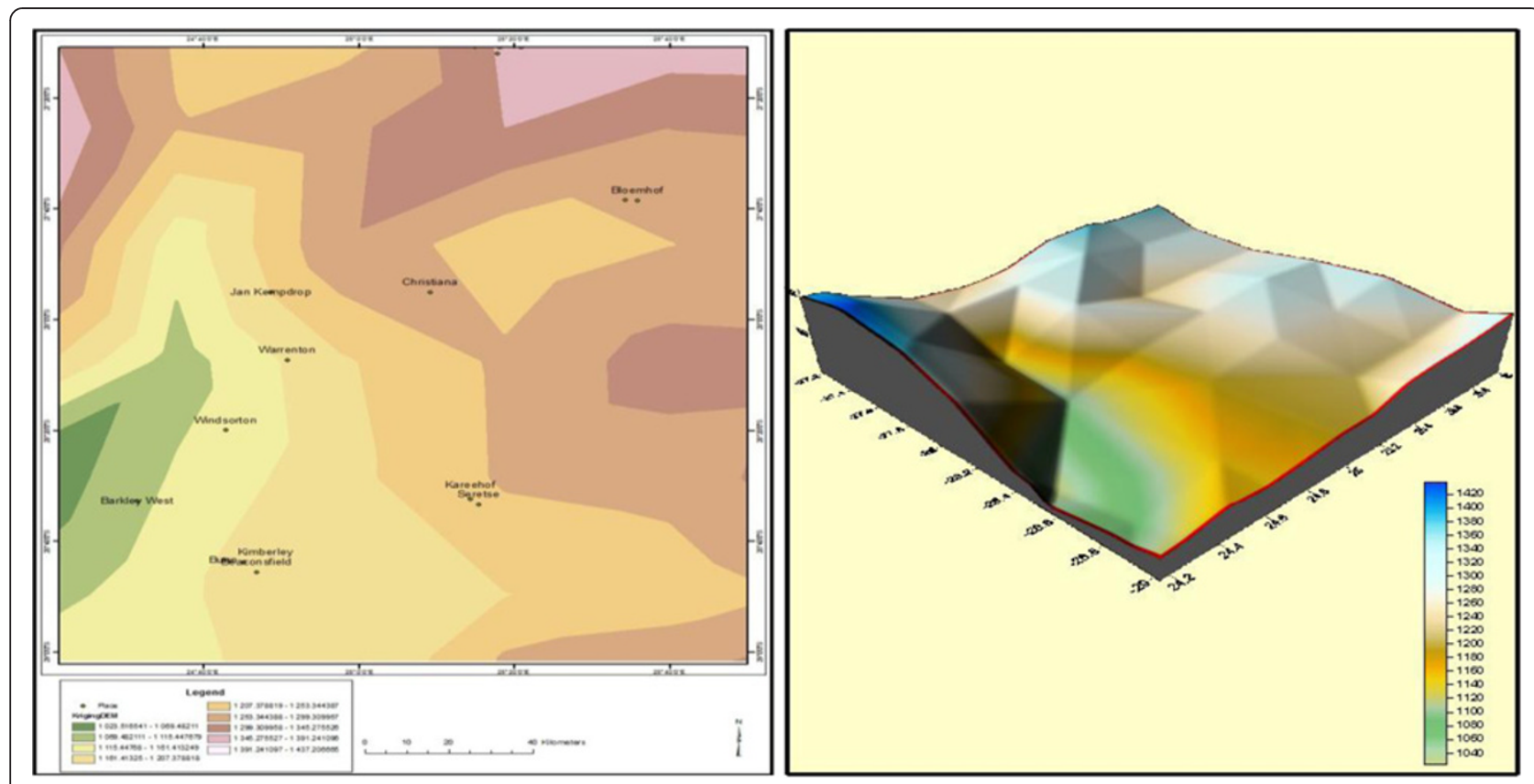

Figure 10 Digital Elevation Model (DEM) and 3D view developed. Source: GIS analysis.

Earth. The SI, NDSI and NDVI indices described in equations 1, 2 and 3 were used for salinity classification and quantification is computed as follows:

$$
S I=\left(\frac{\text { Band } 3}{\text { Band } 4}\right)
$$

$$
\begin{aligned}
& \text { NDSI }=\left[\left(\frac{\text { Band } 3-\text { Band } 4}{\text { Band } 3+\text { Band } 4}\right)\right] \\
& N D V I=\left[\left(\frac{\text { Band } 4-\text { Band } 3}{\text { Band } 3+\text { Band } 4}\right)\right]
\end{aligned}
$$

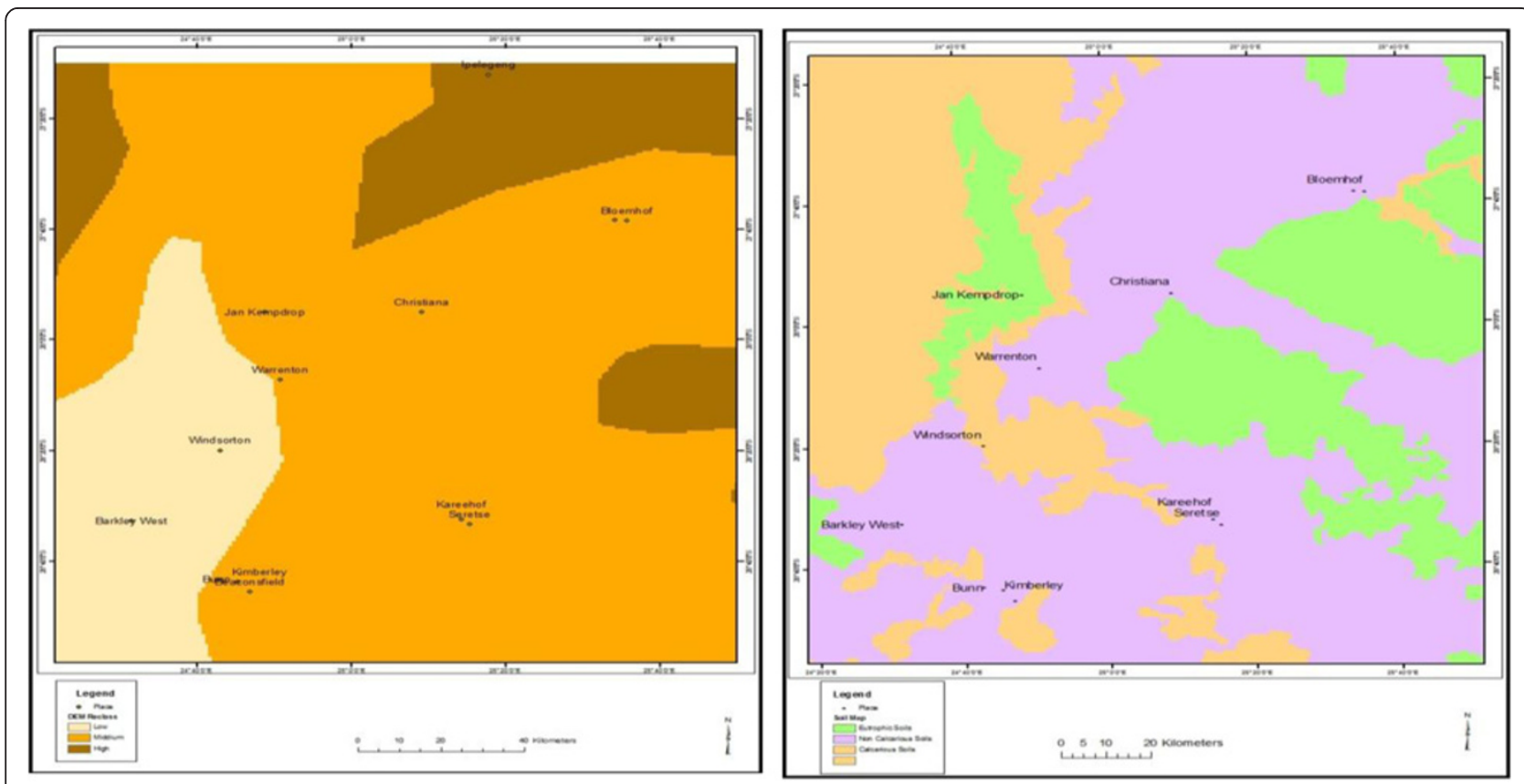

Figure 11 Reclassified DEM and Soil distribution map developed. Source: GIS analysis. 

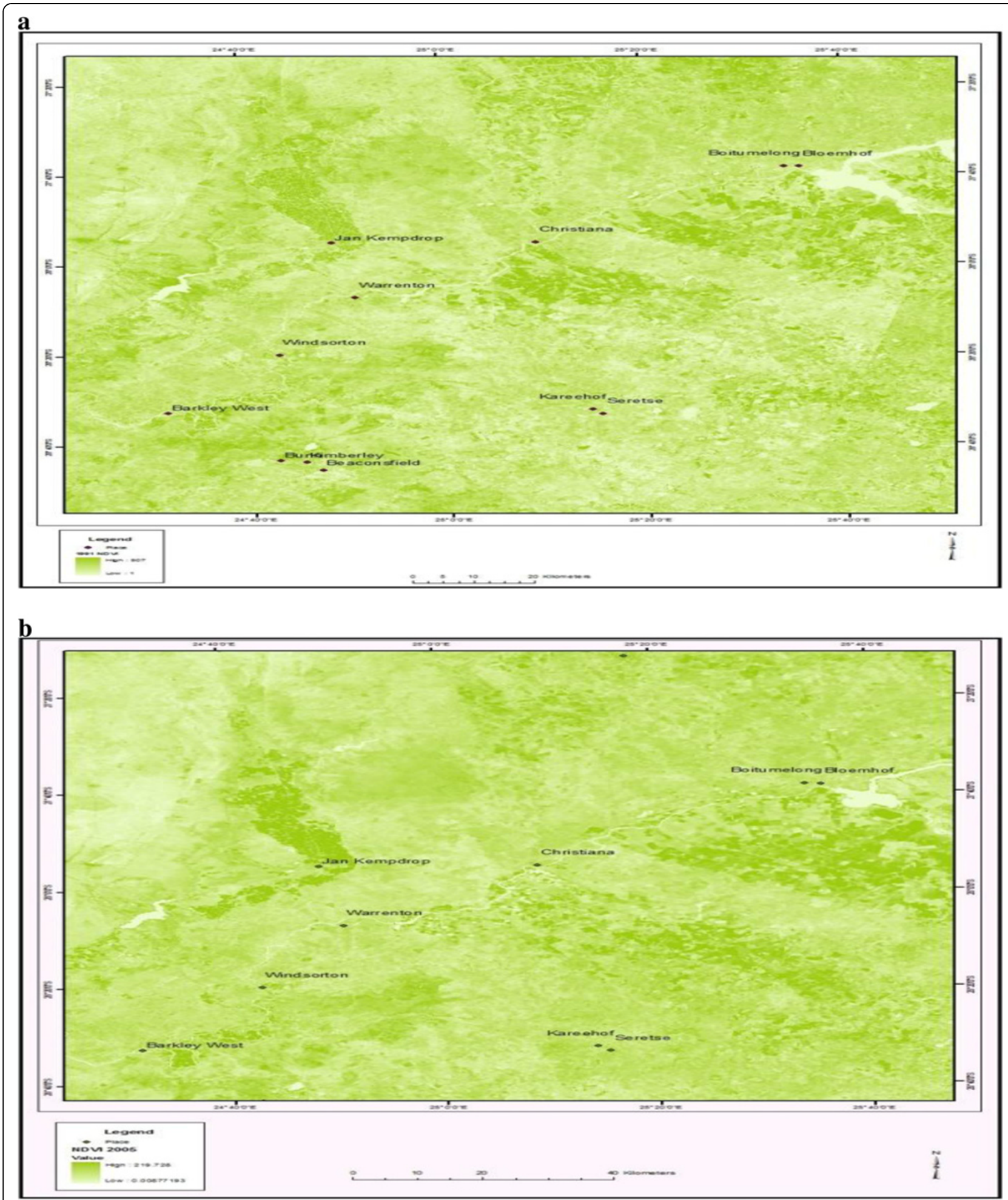

Figure 12 a: Normalised Difference Vegetative Index (NDVI) 1991. Source: GIS analysis. b: Normalised Difference Vegetative Index (NDVI) 2005. Source: GIS analysis. 


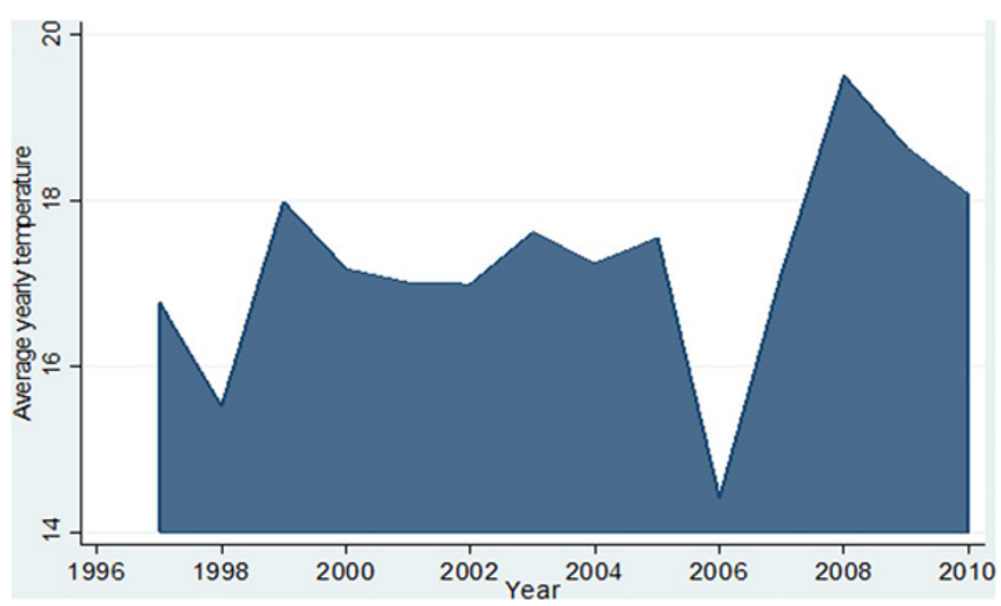

Figure 13 Average yearly temperature for the study area (1997-2010).

To delineate and ground truth the data, a Garmin handheld GPS Receiver of $2 \mathrm{~m}$ accuracy was used to obtain geographical coordinate of water logged and salt affected area. The geographical coordinates were transformed to the Hartebeesthoek94 Datum and converted to ground coordinates. Supervised classifications were performed after extracting spectral signatures and training data sets were created.

\section{Results and discussion}

The Digital Elevation Model (DEM) and 3D views were developed during the GIS analysis as shown in Figures 10 and 11 in order to have a contour of the VHS and thus the location of the waterlogged lands which directly influence land use and salinity development. The NDVI maps are as shown in Figures 12a and b. The results of the vegetation index (NDVI) indicated rather scarce vegetation as

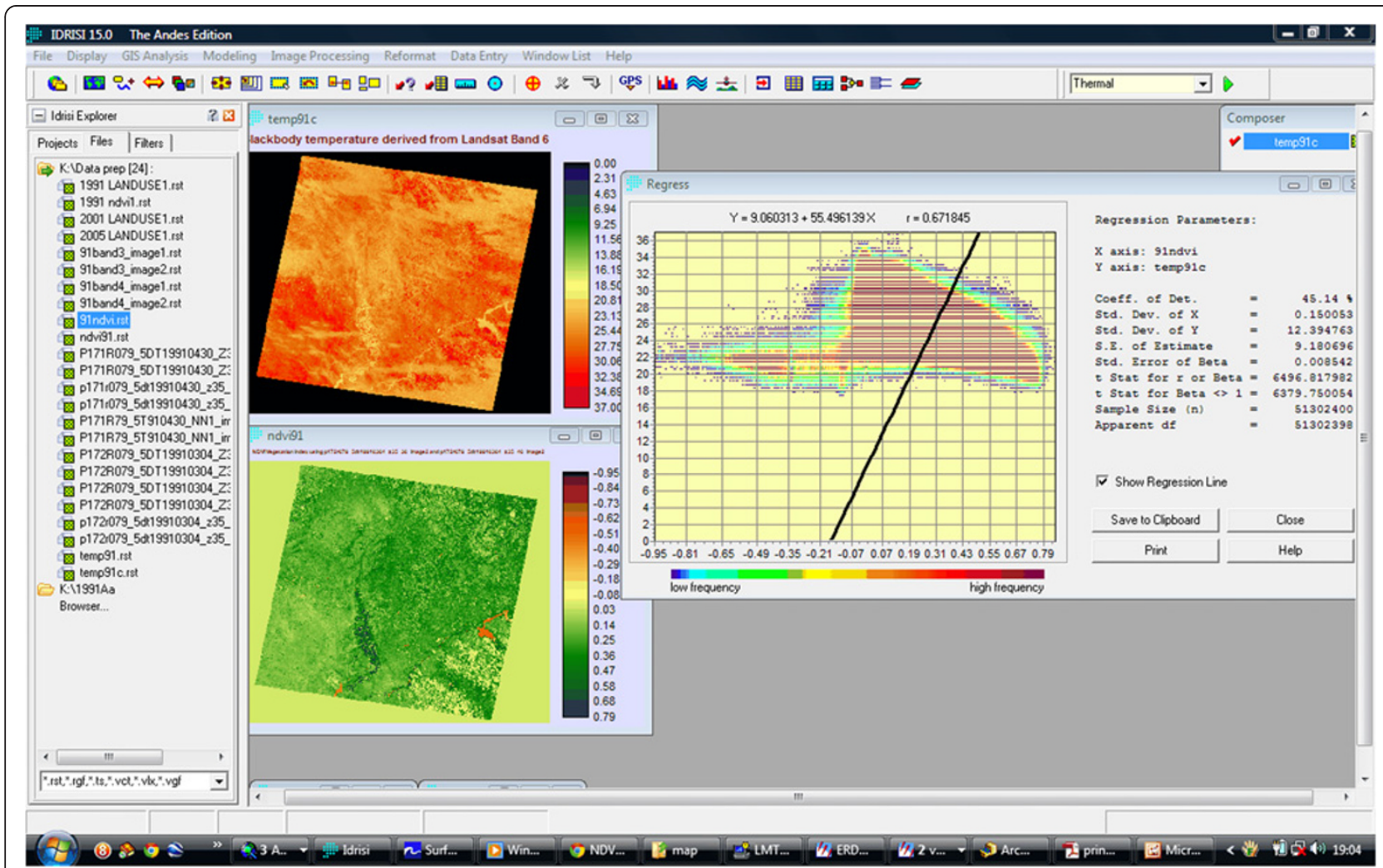

Figure 14 NDVI and temperature plot giving $67 \%$ correlation. 


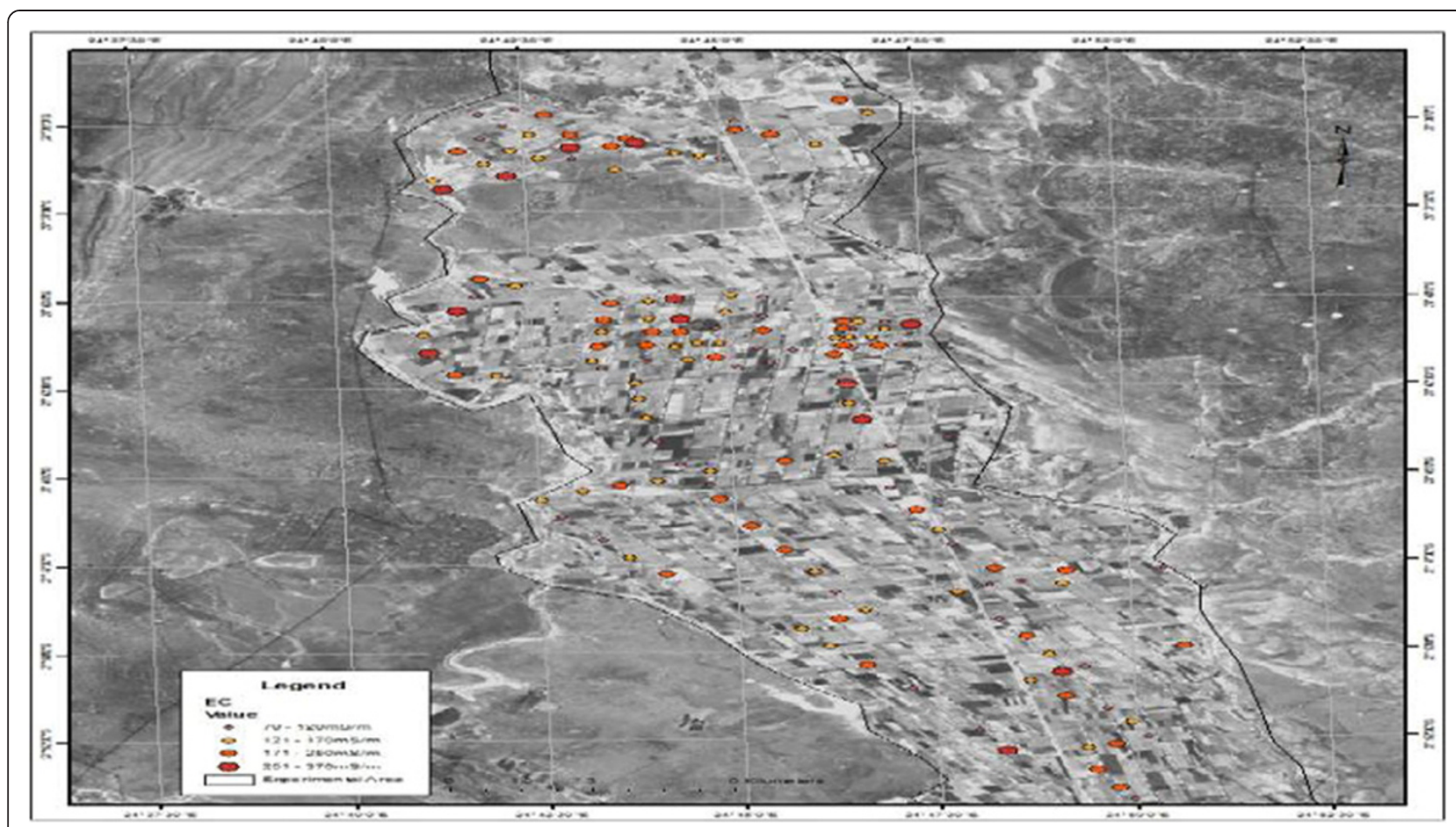

Figure 15 Flood line showing electrical conductivity variation in the study area. Source: GIS analysis.

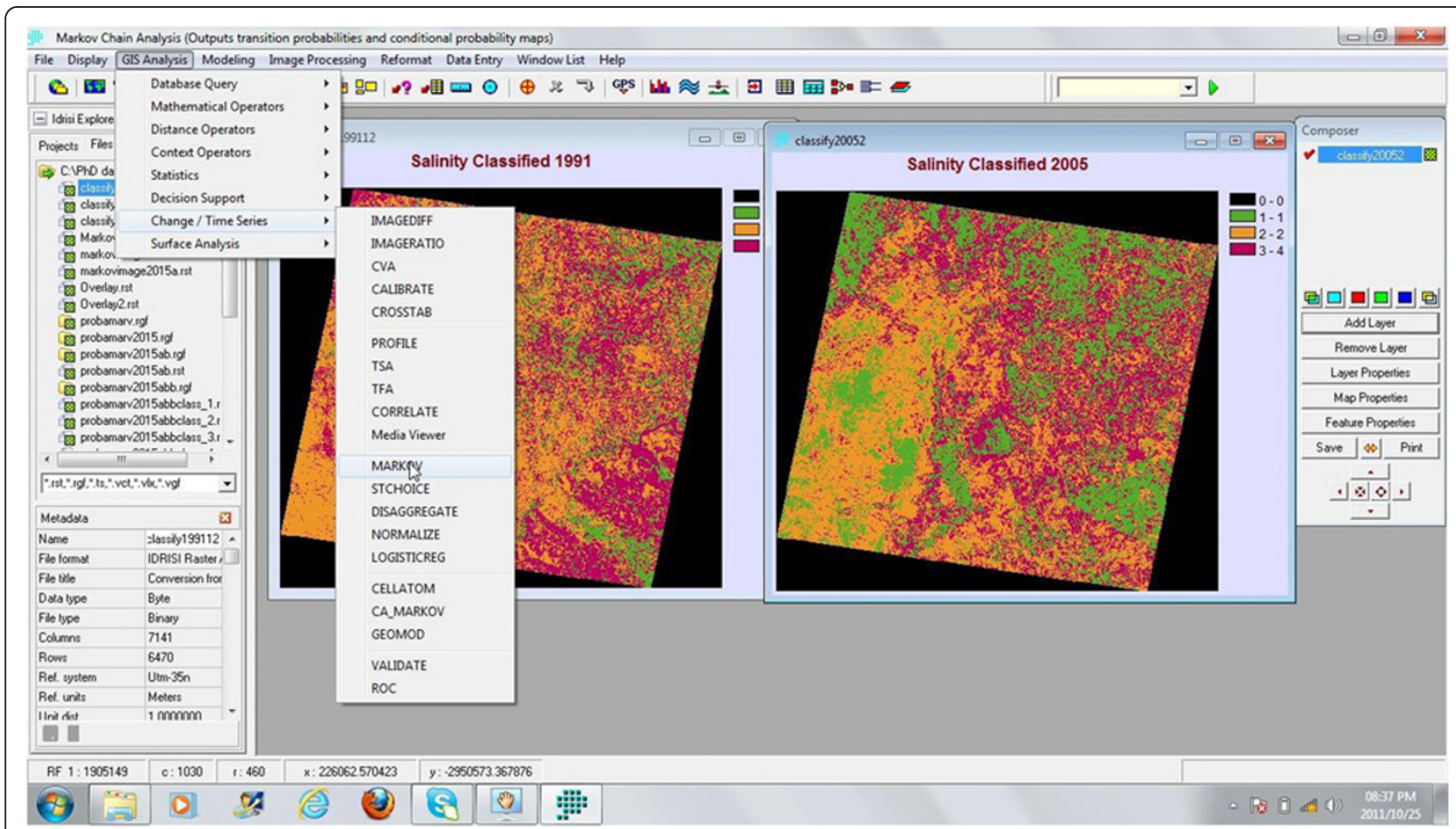

Figure 16 Processing of the Landsat data using IDRISI. 


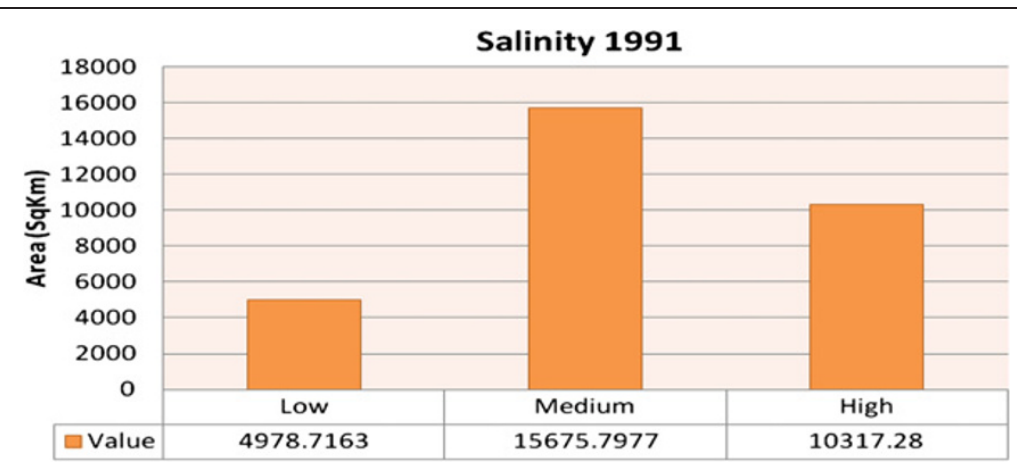

Figure 17 Salinity assessment in IDRISI for 1991.

a whole in the highly saline soils. Minimum to lower threshold represented a negative change in NDVI, lower to upper threshold represented no change in NDVI, upper threshold to maximum value represented positive change in NDVI.

Figure 13 shows average yearly temperature in the study area (1997-2010). For temperature patterns, January was discovered to be the warmest month with maximum and minimum temperatures of $32.7^{\circ} \mathrm{C}$ and $17.4^{\circ} \mathrm{C}$. July is the coldest month with minimum day temperature to be $2.4^{\circ} \mathrm{C}$. Common to VHS is the significant difference between the maximum and minimum temperatures as the seasons change. These results confirmed the finding of Arvind and Nathawat (2006) that land use and land cover pattern are generally influenced by agro climatic variables like temperature, ground water potential and a host of other factors. A plot of NDVI values (from Figures $12 \mathrm{a}, \mathrm{b}$ and $\mathrm{c}$ ) and temperature trend from Figure 13 give a correlation of $67 \%$ showing the effect of temperature on the rate of vegetation/salinity level in the area as shown in Figure 14. This is an indication that temperature is a major factor in the build up of salinity in the study area. Figure 15 also shows the flood line used to determine the electrical conductivity (ECe) in the field. Electrical conductivity is an indicator of salinity.
Imputing NDVI, ECe and Temperature data together and further processing using IDRISI software as illustrated in Figure 16, the overall assessment occurrence pattern of salt-affected soils is derived through supervised classification method. The classification later was grouped into salinity classes of low, medium and high as shown in Figures 17 and 18. For year 1991, the salinity covered 4,978.7 $\mathrm{km}^{2}, 15,675.8 \mathrm{~km}^{2}$ and 10,317.3 $\mathrm{km}^{2}$ (low, medium, high respectively) and by year 2005 (a total of 15 years), it has covered 9,740.5 $\mathrm{km}^{2}, 11,399.4 \mathrm{~km}^{2}$ and 9,831.9 $\mathrm{km}^{2}$ (low, medium, high respectively). This means that low salinity class has increased by $4,8618 \mathrm{~km}^{2}$, while medium and high salinity classes decreased by $4,296.4 \mathrm{~km}^{2}$ and $485.4 \mathrm{~km}^{2}$ respectively. This decrease is a result of continuous control measures in place which mainly focus on the high salinity area in the scheme. In overall, there is an increase in the salinity trend over the years and it is still on the increase.

The supervised classification made use of 15 training sites per habitat identified on the image. As a rule there should be an adequate sample of pixels for each cover type for statistical characterization. A general rule of thumb is that the number of pixels in each training set (i.e., all the training sites for a single cover class) should not be less than ten times the number of bands. Hence, the use of three bands in

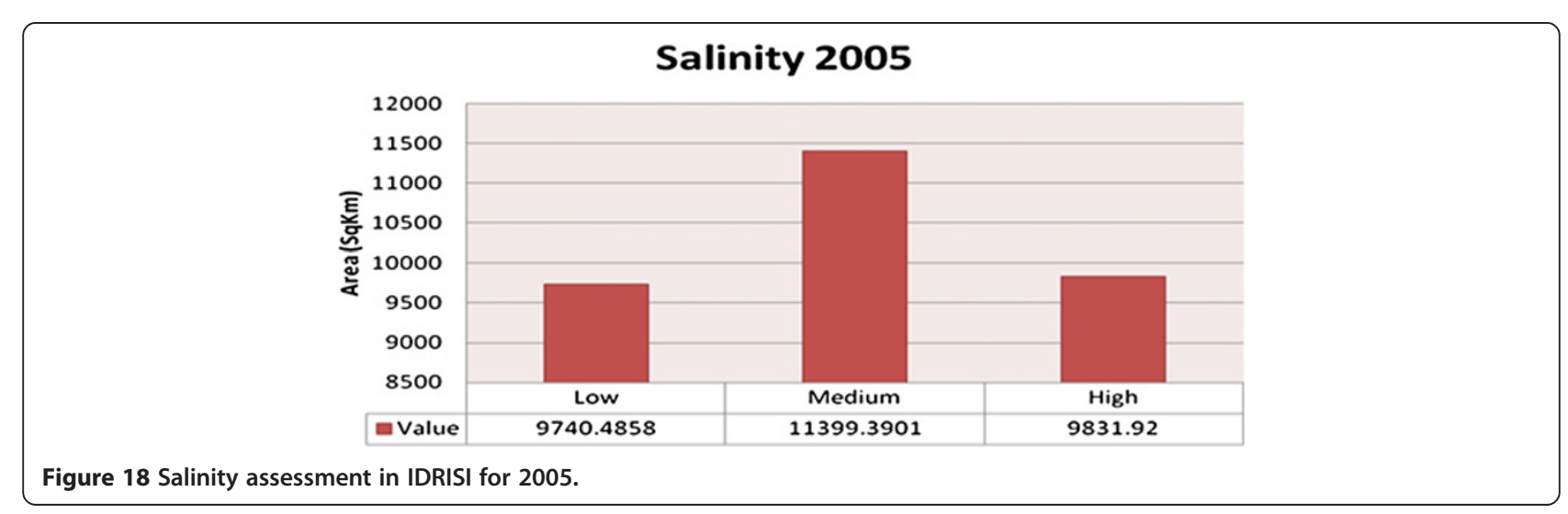


the classification processes with 45 training sites in each cover type, each has fifteen classes.

The band 3 (red band) provides the best separation for vegetation, while band 4 (near infrared band) provide the best separation for the area with salt, while water is distinct in all the bands. Band 4 provided a better separation of the area occupied by salt than band 5 (middle infrared band). Bands 4 performed better when it comes to the spectral separation of areas dominated by salt but band 3 was extremely excellent in the vegetation discrimination. The spectral signatures also aided in the classification processes of salinity, community/built-up, vegetation and water swamp areas.

\section{Conclusion}

Soil salinity is a critical environmental problem which has great impact on soil fertility and overall soil productivity. Remote sensing was proved useful in detecting salinity trend using Landsat enhanced thematic mapper plus $(\mathrm{ETM}+)$ data along with other field data and topographical maps to show the spectral classes and areas of salt-affected for the years under assessment. Detection of salinization, assessment of the degree of severity and the extent particularly in its early stage is vital as it was also shown in the results indicating a gentle increase in the rate. The results of the study indicated that a serious salinity problem exists on VHS and this may get worse unless more effort is geared toward effective management of the menace. This is in agreement with findings of Zuluaga, 1990; Vincent et al., 1996; Dehaan and Taylor, 2002 that field derived spectra of salinised soils and vegetation indexes are good indicators of irrigation induced soil salinisation for identification of saline soil regions.

The Normalized Difference Vegetation Index (NDVI) and temperature plot gave a correlation of $67 \%$ which is a good indicator of salinity trends. This can be improved on by combining detailed field measurements using a handy hyper spectrometer to increase the accuracy of detection. This is an indication that temperature is an important environmental factor in the build up of salinity in areas known with high temperature (semi-arid climatic zone in which the study area fell into). Conclusively, there is an urgent need for the establishment of management program to control the spread of this menace, thereby reclaiming the damaged land in order to make the scheme more economically viable.

\section{Competing interests}

The authors declare that they have no competing interests.

\section{Authors' contributions}

GM Ochieng: Analysis Of The Data, Field Supervision, Editing Of The Manuscript. O I Ojo: Carried Out Field Work And Data Collection, Analysis Of The Data And Drafted The Manuscript. FAO Otieno: Overall Supervision,
Editing Of The Manuscript. B Mwaka: Field Project Supervision, Editing Of The Manuscript. All Authors Read And Approved The Final Manuscript.

\section{Acknowledgement}

The authors are thankful to the Tshwane University of Technology, Pretoria, South Africa for providing financial support which made this study possible. The support of the Vaal Harts irrigation water users association, Agricultural Research Council (ARC) and Department of water and environmental affairs is acknowledged for providing some data.

\section{Author details}

'Dept. of Civil Engineering, Tshwane University of Technology, Pretoria, South Africa. ${ }^{2}$ Technology, Innovation and Partnerships Unit, Durban University of Technology, Durban, South Africa. ${ }^{3}$ Dept. of Water and Environmental Affairs, Pretoria, South Africa.

Received: 8 November 2012 Accepted: 15 January 2013 Published: 25 February 2013

\section{References}

Brogaard S, Prieler S (1998) Land cover in the Horgin grasslands, North China. Detecting changes between 1975 and 1990 by means of remote sensing. Interim report IR-98-044/July on work of the International Institute for Applied System Analysis

Dehaan RL, Taylor GR (2002) Field-derived spectra of salinized soils and vegetation as indicators of irrigation-induced soil salinization. J Remote Sensing Environ 80(3):406-417

Du P H M (1991) Researching and applying methods to conserve natural irrigation resources. Proceedings of South Africa Irrigation Symposium 61-69. June 1991, Durban, South Africa

Ernani MZ, Gabriels D (2006) Detection of land cover changes using Landsat MSS, TM, ETM+ sensors in YHazd-Ardakan basin. Proceedings of Agro Environ 2006, Iran, 2006

Grove B (2006) Generalised whole-farm stochastic dynamic programming model to optimise agricultural water use. Report to the Water Research Commission, Pretoria

Jager JM (1994) Accuracy of vegetation evaporation formulae for estimating final wheat yield. Water SA 20:307-314

Latifovic R, Fytas K, Chen J, Paraszczak J (2005) Assessing land cover change resulting from large surface mining development. Int J Appl Earth Observation Geoinformation 7:29-48

Ojo Ol, Otieno FAO, Ochieng GM (2009) Irrigation Problems and Research needs in South Africa: A review of the Vaal Harts Irrigation Scheme. World Academy of Science, Engineering and Technology WCSET Conference, September 23-25, 2009., Amsterdam. ISBN ISSN 2070-3740

Ojo Ol, Ochieng GM, Otieno FAO (2011) Assessment of water logging and salinity problems in South Africa: an overview of Vaal Harts irrigation scheme. WIT Transactions on Ecology and the Environment, Volume 153., WIT Press. ISBN ISSN 1743-3541

Tripathi NK, Rai BK, Dwivedi P (1997) Proceedings. Of 18th Asian Conference in Remote Sensing, October, 1997., Kuala Lumpur, Malaysia, pp A-8-1-A-8-6

Van Trinh M, Duong ND, Van Keulen H (2004) Using Landsat images for studying land use dynamics and soil degradation: Case study in Tamduong District. International Symposium on Geoinformatics for Spatial Infrastructure Development in Earth and Allied Sciences, Vinhphuc Province, Vietnam, 2004

Vincent B, Vidal A, Tabbet AB, Kuper M (1996) In: Vincent B (ed) Use of satellite remote sensing for the assessment of water logging or salinity. An Evaluation of performance of subsurface drainage systems: $16^{\text {th }}$ Congress on Irrigation and Drainage, Cairo, Egypt, 15-22 September, 1996. International Commission on Irrigation and Drainage, New Delhi, pp 203-216

Zuluaga JM (1990) Remote sensing applications in irrigation management in Mendoza, Argentina. In: Menenti M (ed) Remote sensing in the evaluation and management of irrigation. Instituto Nacional de Cienciay Tecnic, Mendoza, Argentina, pp 37-58

doi:10.1186/2193-2697-2-4

Cite this article as: Ochieng et al:: Use of remote sensing and geographical information system (GIS) for salinity assessment of VaalHarts irrigation scheme, South Africa. Environmental Systems Research 2013 2:4. 